\title{
Intramedullary cystic lesions of the conus medullaris
}

\author{
SAMI I. NASSAR, JAMES W. CORRELL, AND \\ EDGAR M. HOUSEPIAN \\ From the Department of Neurosurgery, College of Physicians and Surgeons, \\ Columbia University, and the Neurological Institute of the \\ Columbia-Presbyterian Medical Center, New York, U.S.A.
}

Intramedullary cystic lesions of the conus medullaris are rare. Although an extensive literature describes syringomyelia as being a frequent basis for cystic cervico-thoracic lesions it is apparent that this does not occur frequently in the lumbosacral region (Kirgis and Echols, 1949; Netsky, 1953; Rand and Rand, 1960; Love and Olafson, 1966). Poser (1956), in a review of 234 cases of syringomyelia, found that the cavity extended into the lumbosacral region in only $12.6 \%$ and in only five cases were the cavities restricted to the lumbosacral segments. Some authors (Thévenard, 1942; André, 1951) question the occurrence of syringomyelia in the lower spinal cord. Nevertheless a high incidence of constitutional defects has been noted among syringomyelia patients and members of their families, the most frequent of which are spina bifida occulta, pes cavus, syndactylism, and chest deformities (Henneberg and Koch, 1923; Chavany and Thiébaut, 1933; Thévenard and Coste, 1935; Jackson, 1949). These defects have been found to occur at times with cystic cavitations of the lumbosacral region, lending support to the developmental aetiology of at least some intramedullary cysts.

Localized cysts of the conus and epiconus have also been reported in association with trauma, tumours, and vascular disease (Kirgis and Echols, 1949; Netsky, 1953; Hughes, 1966). Haemorrhage into the substance of the cord has been described as a cause of cavitary disease following severe trauma. Liquefaction of the haemorrhage results in the formation of a fluid-filled cavity that may remain unchanged or slowly enlarge at the expense of functioning neural elements. Sudden haemorrhage, of course, results in a rapid progression of neurological symptoms and the syndrome of haematomyelia.

Cavitations may also be produced by vascular impairment to the cord structure from extraneural inflammatory or compressive pathology. Another process of cyst formation may be ischaemic necrosis of the cord with resulting liquefaction. Irrespective of the aetiology, these cysts may simulate the clinical picture of syringomyelia.

The cases of cysts of the conus medullaris reported here simulated the clinical picture of syringomyelia, tumour, or lumbar disc disease. The radiographic findings in each case were interpreted as indicating the presence of an intramedullary tumour. The correct diagnosis was made in each case only at operation.

\section{CASE REPORTS}

CASE 1 (F.T., No. 17916 92) A 22-year-old negro male was admitted complaining of weakness and pain in the legs for three years. The pain began in the right foot and progressed in nine months to involve both lower limbse There was an associated feeling of numbness of both feet.

One year before admission he complained of persisten low backache which radiated to the right thigh and calf This was followed by difficulty in voiding. The patient also observed a progressive bilateral deformity of the feet (pes cavus). His past medical history contributed nothing.

General physical examination was normal. On neurological examination this asthenic young man was found to have bilateral foot drop. There was diffuse weakness of both lower extremities, most marked in the calf muscles. There was wasting of the small muscles of both feet, more pronounced on the right. The Achilles reflexes were absent. The appreciation of pain and light touch was decreased up to the level of $\mathbf{L 3}$ bilaterally, but the third to the fifth sacral dermatomes were spared. Laboratory studies were normal. The cerebrospinal fluid contained $17 \mathrm{mg}$ protein $100 / \mathrm{ml} . / \mathrm{cu} . \mathrm{mm}$ and 1 W.B.C.

Pantopaque myelography showed evidence of an intramedullary tumour of the conus (Fig. 1a). At laminectomy (T11-L1) a $2 \times 2 \mathrm{~cm}$ intrinsic mass of the conus was found ending in the filum (Fig. 1b). The nerve roots were stretched over the mass, which was cystic. A number 26 needle was inserted into the mass and $4 \mathrm{ml}$. of colourless fluid was aspirated. The mass collapsed and the nerve roots became relaxed. A $1 \mathrm{~cm}$ linear incision made in the dorsal midline of the conus allowed inspection of the cavity in which there was no gross evidence of tumour, 


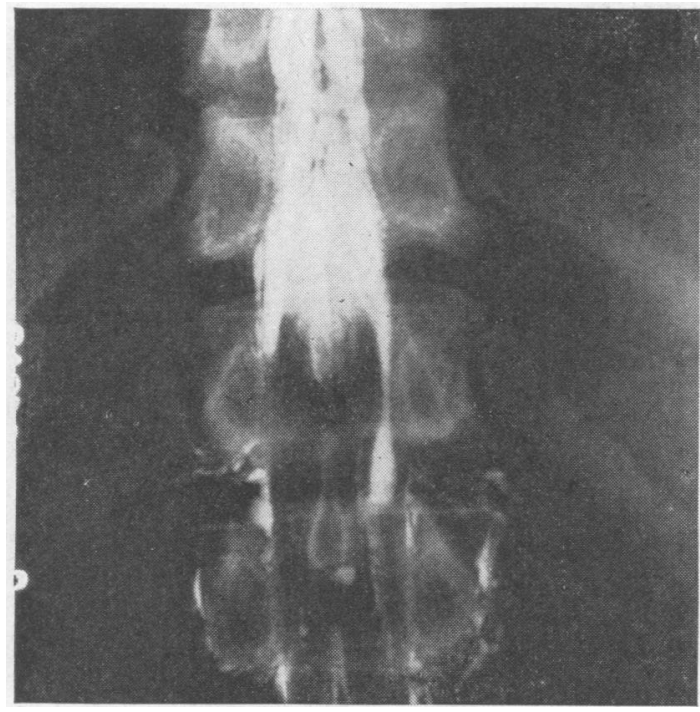

FIG. 1a. Case 1: myelographic demonstration of the intramedullary mass defect at the level of T12-L1.

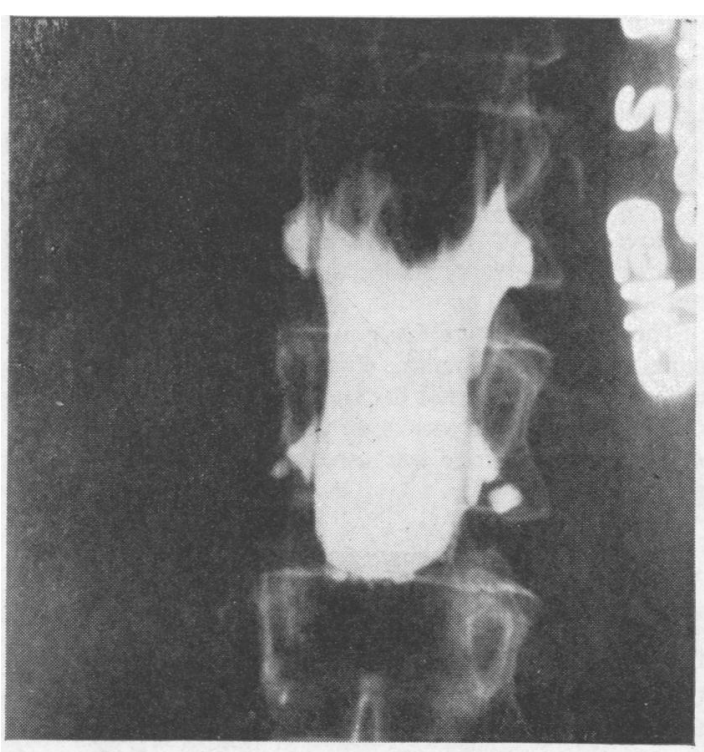

FIG. 2a. Case 2: myelographic demonstration of a fusiform intramedullary tumour at the level of T12-L1 with a complete block to the flow of Pantopaque above.

and cell block of the cyst fluid was negative for tumour cells. No biopsy of the cyst wall was done. The postoperative course was uneventful. A follow-up of seven months showed an improvement in motor, sensory, and blarder function.

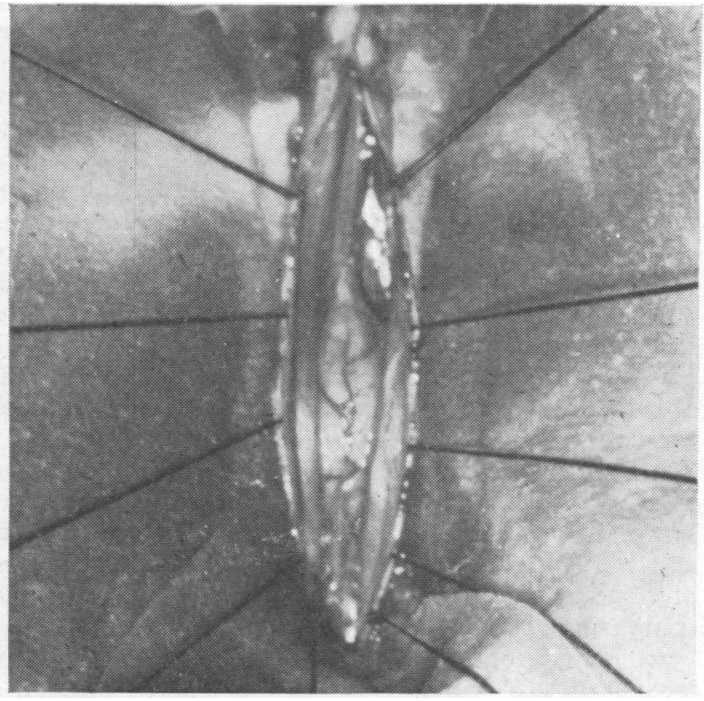

FIG. 1b. Case 1: an intrinsic cystic mass of the conus with the stretched nerve roots overlying it exposed at operation.

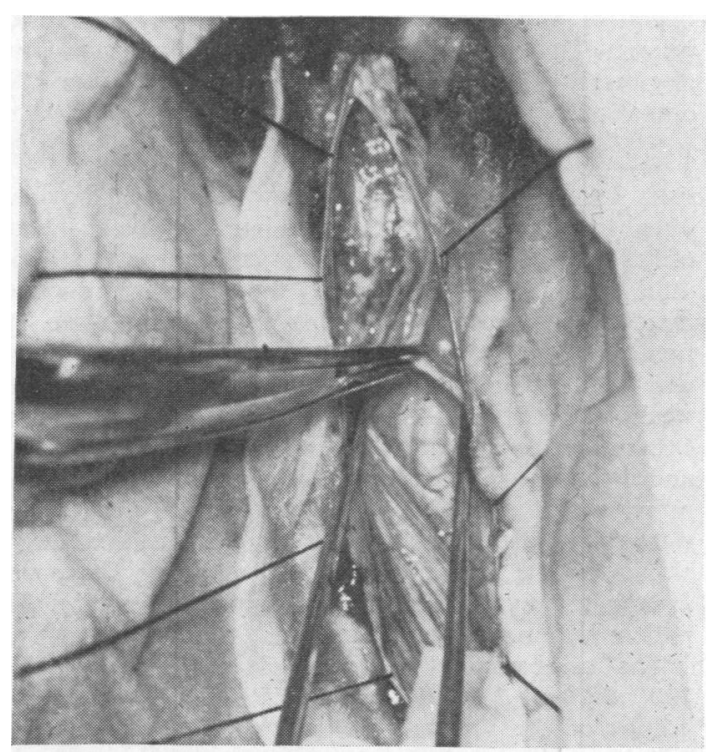

FIG. 2b. Operative photograph showing a cyst of the conus which has been opened and its cavity exposed.

CASE 2 (C. D., NO. 17492 23) A 51-year-old woman was admitted because of episodic low back pain with radiation to the right lower extremity for eight years. In December 1963 the patient noted weakness in the right leg. In 1964 a 'disc operation' carried out in another hospital was 
followed by temporary alleviation of the low back pain but she continued to complain of weakness in the right leg and began to have numbness of the right foot and toes. Several months before this admission the patient also complained of pain in the left leg. Her past medical history contributed nothing.

On physical examination there was flattening of the lumbar lordosis with moderate paraspinous spasm and tenderness in the lumbar region. There was a right foot drop with wasting of the anterior and posterior tibial peronei and extensor hallucis longus muscles on the right. Hypaesthesia was noted in the L5 dermatome in the right foot. The right Achilles tendon reflex was absent. The rest of the neurological examination was normal.

Laboratory data were normal. A radiograph of the spine showed slight narrowing of the lumbosacral interspace. The cerebrospinal fluid protein level was $28 \mathrm{mg} /$ $100 \mathrm{ml}$. W.B.C. 1; R.B.C. O/cu.mm. A Pantopaque myelogram revealved a large tumour of the conus with complete block at T12-L1 (Fig. 2a).

At laminectomy (T11-L1) a large cyst of the conus medullaris was found. The cyst was entered through a thinned portion of the conus and $15 \mathrm{ml}$. of clear, colourless watery fluid was drained. Careful inspection of the cavity failed to reveal evidence of tumour (Fig. 2b). Biopsy of the cyst wall was negative for tumour and showed only fragments of white matter. In the postoperative period, numbness and pain gradually disappeared. The strength of the right leg improved with physiotherapy. The patient is doing well one year after operation.

CASE 3 (A. L., No. 15874 76) A 16-year-old boy was noted to have a mild thoraco-lumbar scoliosis at the age of 3. He was well and engaged in various sport activities until he was 14 years old when the scoliosis progressed rapidly. In June of 1962 a spinal fusion from T6 to T11 was done. On the second post-operative day the patient was unable to move his lower limbs: there was diffuse weakness and spasticity of the muscles of the lower extremities, most marked in the quadriceps, hamstrings and iliopsoas on the left and the plantar and dorsiflexor muscles of the left foot were profoundly weak. There were bilateral Babinski signs and unsustained ankle clonus on the right. Position and vibration sense were asymmetrically reduced in the lower extremities. The patient required bladder drainage.

The cerebrospinal fluid protein level was $51 \mathrm{mg} /$ $100 \mathrm{ml}$., and 1 W.B.C. and 5 R.B.C./cu.mm. Radiographs of the vertebral column showed marked right T11-12 scoliosis. A myelogram showed an expanded cervical-thoracic cord with an additional bulbous expansion localized at the conus medullaris. The findings were interpreted as either a diffuse syrinx or an ependymoma.

A T11-12 laminectomy revealed a rounded, lobulated cystic mass adherent to the inferior aspect of the conus medullaris. It became attenuated inferiorly, being attached to the filum terminale for a distance of $3.5 \mathrm{~cm}$. The cyst had a thin, transparent wall and contained clear fluid (Fig. 3). Superiorly the cyst was continuous with a

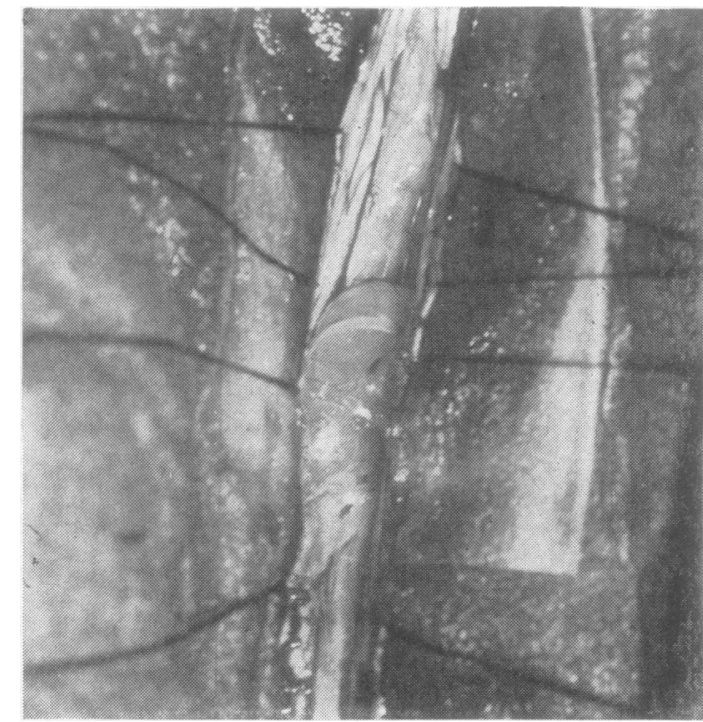

FIG. 3. Case 3: operative exposure of a rounded lobulated cystic mass adherent to the inferior aspect of the conus medullaris.

rounded opening, suggesting a greatly dilated centraf canal, in the conus medullaris. A subtotal excision of theD cystic lesion was done and the conus medullaris and cauda equina were decompressed.

Microscopic examination of the cyst removed afo operation showed that the wall of the cyst was formed bo a layer of ependymal cells situated along one surface of narrow bands of glial tissue and it was concluded that this was a cystic congenital malformation of the filum terminale.

The post-operative course was uneventful except for a urinary tract infection. Post-operatively the boy was able to walk unassisted for short distances. In December of 1966 the patient was reported to be attending college. Although a leg brace was used he was able to carry out all desired activities.

\section{DISCUSSION}

These patients presented with interesting and similar features. All three had lumbar pain and paresis of the lower extremity, thought to be related to tumour, intervertebral disc disease, and syringomyelia respectively. The myelographic findings in these patients showed intramedullary lesions interpreted as being consistent with conus ependymoma. The finding at operation of localized cysts of the conus medullaris filled with colourless, cystic fluid in the three cases was unexpected. The protein concentration and cytological examination of the cystic fluid and biopsy of the cyst wall was not consistent with tumour as an underlying cause. 
In the first case, a cystic cavity was found entirely limited to the conus medullaris. A biopsy of the cyst wall unfortunately was not obtained. A neoplastic process seemed unlikely in view of a normal protein determination and a negative cytological examination of the cyst fluid. The findings in the second case suggested the presence of a syrinx in the conus medullaris because of the clear fluid filling the cyst and the biopsy of the cyst wall which revealed only fragments of white matter without an inner ependymal lining. There was no opening from the cavity to suggest continuity with the central canal. In the third case the cyst projected from the tip of the conus medullaris in between the roots of the cauda equina. The enlarged conus noted at operation contained a greatly dilated central canal which opened inferiorly and its ependymal lining was continuous with the lining of the wall of the cyst. The fact that diffuse widening of the upper spinal cord was seen by myelography suggests that the intramedullary cystic process extended superiorly, and it seems possible that the hydromyelic cavity extended the full length of the spinal cord. This might fit into Gardner's theory of a developmental anomaly of the hind-brain and failure of the foramen of Magendi to open (Gardner, 1965).

The relationship of intramedullary cysts to neoplasms remains unclear. Necrosis within the core of the tumour, circulatory insufficiency, and oedema of the adjacent cord structure may result in intrinsic localized cavitation. The surgical and pathological findings in these three cases do not support these possibilities.

The slow clinical deterioration indicates a progressive process. Enlargement of the cyst is thought to be the basis for the increasing neurological deficits and indicates that the cystic fluid was under pressure causing compression of the roots of the cauda equina. Drainage by incision and permanent communication of the cyst cavity with the subarach- noid space is the treatment of choice (Kirgis and Echols, 1949).

In all three cases post-operative follow-up of seven months, 18 months, and five years respectively has shown substantial improvement of motor and sphincteric function.

\section{SUMMARY}

Non-neoplastic cystic lesions of the conus medullaris have been shown to simulate tumour, syringomyelia, and lumbar disc disease. Although the pathology has been localized by myelography, the diagnosis has been made only at operation. Surgical exploration, drainage, and decompression has resulted in improvement and is the recommended treatment.

\section{REFERENCES}

André, M. J. (1951). Études sur la syringomyélié. Acta neurol. Psychiat. Belg., 51, 665-696.

Chavany, J. A., and Thiébaut, F. (1933). Panaris analgésiques du pied droit par syringomyélie lombo-sacrée unilatérale chez un enfant de 11 ans. Rev. Neurol., 1, 176-182.

Gardner, W. James (1965). Hydrodynamic mechanism of syringomyelia its relationship to myelocele. J. Neurol. Neurosurg. Psychiat., 28, 247-259.

Henneberg, R., and Koch, M. (1923). Zur Pathogenese der Syringomyelie und über Hämatomyelie bei Syringomyelie. Mschr. Psychiat. Neurol., 54, 117-140.

Hughes, J. Trevor (1966). Pathology of the Spinal Cord, p. 32. LloydLuke, London.

Jackson, M. (1949). Familial lumbo-sacral syringomyelia and the significance of developmental errors of the spinal cord and column. Med. J. Aust., 1, 433-439.

Kirgis, H. D., and Echols, D. H. (1949). Syringo-encephalomyelia; discussion of related syndromes and pathologic processes, with report of a case. J. Neurosurg., 6, 369-375.

Love, J. G., and Olafson, R. A. (1966). Syringomyelia: a look at surgical therapy. J. Neurosurg., 24, 714-718.

Netsky, M. G. (1953). Syringomyelia: a clinicopathologic study. Arch. Neurol. Psychiat., (Chic.) 70, 741-777.

Poser, C. M., (1956). The Relationship between Syringomyeila and Neoplasm. Thomas, Springfield, Illinois.

Rand, R. W., and Rand, C. W. (1960). Intraspinal Tumors of Childhood. Thomas, Springfield, Illinois.

Thévenard, A. (1942). L'acropathie ulcéro-mutilante familiale. Rev. neurol., 74, 193-212.

probable et spina-bifida occulga sacre. Rev. Neurol., 63, 195-206. 